\title{
Erratum to: Duloxetine for Neuropathic Pain Based on Recent Clinical Trials
}

\author{
David Fishbain • Kim Berman • Daniel K. Kajdasz
}

Published online: 30 July 2011

(C) Springer Science+Business Media, LLC 2011

Erratum to: Curr Pain Headache Rep 2006, 10(3):199-204

DOI 10.1007/s11916-006-0046-7

Fishbain D, Berman K, Kajdasz D.K: Duloxetine for Neuropathic Pain Based on Recent Clinical Trials. Curr Pain Headache Rep 2006, 10:199-204

This article was published in the June 2006 issue of Current Pain and Headache Reports (volume 10, issue 3).

The authors have found errors in Fig. 1 as published, and have provided this corrected figure in remedy.

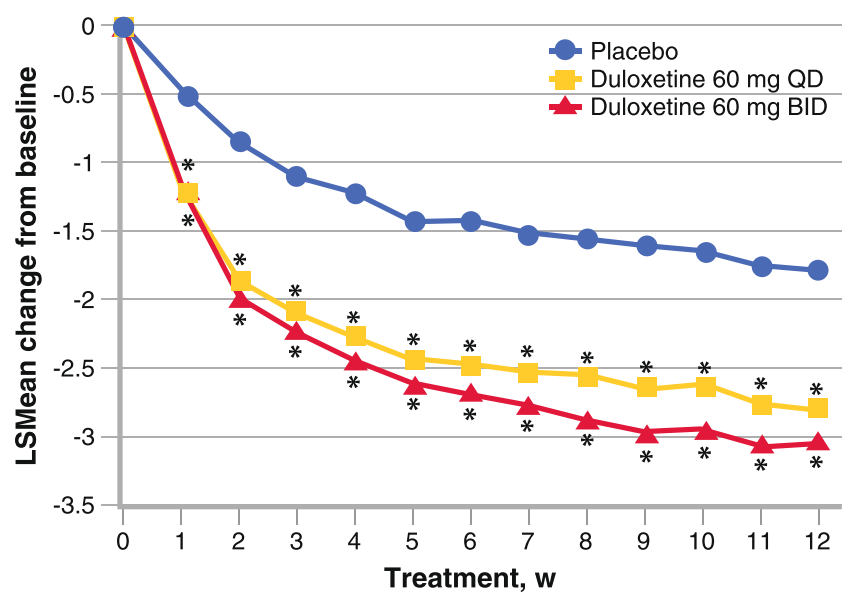

Fig. 1 LSMean change from baseline in average pain score. Improvement in pain score from baseline is shown by a more negative change. Asterisk indicates $P \leq 0.001$ versus placebo. Assessments are based on a mixed-effects repeated measures model including terms for

The online version of the original article can be found at http://dx.doi. treatment, investigator, week, baseline, treatment-by-week, and baseline-by-week org/10.1007/s11916-006-0046-7.

D. Fishbain $(\bowtie)$

Department of Psychiatry and Behavioral Science,

Miller School of Medicine, University of Miami,

1695 Northwest 9th Avenue, Suite 3302L,

Miami, FL 33136, USA

e-mail: dfishbain@med.miami.edu

K. Berman

INK Squared,

Sloansville, NY, USA

D. K. Kajdasz

Dogwood Pharmaceuticals, Inc.,

5 Science Park,

New Haven, CT 06511, USA 